\title{
Building Professional Learning Communities to Enhance Continuing Professional Development in South African Schools
}

\author{
G. M. Steyn \\ Department of Educational Leadership and Management, University of South Africa \\ P O Box 392, Pretoria 0003, South Africa \\ Cell: +2782 886 7468, Fax: +2712664 6802 or +27 124294922 \\ E-mail: steyngm1@unisa.ac.za
}

KEYWORDS Continuous Teacher Development. Policy Frameworks on Professional Development. South Africa

ABSTRACT As part of a developing country South African teachers need to be appropriately developed to meet the growing social and economic needs of the country. The National Policy Framework for Teacher Education and Development and the Integrated Strategic Planning Framework for Teacher Education and Development in South Africa are two initiatives to fulfil the dire need for quality teachers. Since little research has been done on aspects that are important for effective collaboration among teachers, this article attempts to answer the following research problem: How can professional learning communities in schools be implemented effectively to enhance the continuing professional development of teachers in South African schools? A dynamic model of professional learning communities is presented, showing how individual learning, professional development communities, a conducive school environment and networking lead to transformational change in teachers.

\section{INTRODUCTION}

Teaching is considered to be at the heart of school systems and the quality of teachers' practices at the root of quality education (Republic of South Africa 2008: 9). This explains why the continuing professional development of teachers has received extensive international attention in endeavours to implement new and revised curricula, to improve the learning in schools within complex teaching environments and even to improve the overall performance of an education system (Centre for Development and Enterprise 2011: 13; Darling-Hammond et al. 2009: 3; Kitchen 2009: 58; Maistry 2008: 119; Mestry et al. 2009: 476; Murtaza 2010: 215; Nehring and Fitzsimons 2011: 515; Opfer et al. 2011: 194; Sigurðardóttir 2010: 395; Supovitz, et al. 2010: 34; West 2010: 95).

The legacy of apartheid has severely impacted the culture of professional development among teachers in South African schools (Mestry et al. 2009: 476). The Centre for Development and Enterprise (2011: 8) states that school systems in South Africa are 'underperforming' and that teachers are the main reason for the bleak performance of these schools. The study therefore concludes that "Teachers are at the centre of South Africa's struggling school system” (Centre for Development and Enterprise 2011: 29). As such South Africa is in dire need of more and better qualified teachers.

Many countries, such as the Netherlands, Singapore, South Korea and Sweden, have established national requirements for teachers' continuing professional development (DarlingHammond et al. 2009: 17). However, these 'experiences underscore the importance of on-the-job learning with colleagues as well as sustained learning from experts in content and pedagogy' since the focus is predominantly on individual learning (Darling-Hammond et al. 2009: 17). Although Opfer et al. (2011: 210) claim that there is merit in individual learning, they argue that 'teacher learning is a dynamic process and cannot be understood by separating the professional development of teachers from the environments in which teachers undertake their learning' (Opfer et al. 2011: 196).

Sigurðardóttir (2010: 407) and Nehring and Fitzsimons (2011: 526) believe that isolated teaching practices are counterproductive for improving teaching practices, while interdependency is a requirement for teachers' collaborative learning and more effective teaching practices. West's study (2010: 101) also reveals that teacher collaboration assists in reducing polarisation within the school system, which in particular benefits those students who are not performing satisfactorily and who are on the periphery of the school system. According to Hirsh (2012: 
64), successful professional learning communities (PLCs) enhance the sharing of effective practices between teachers and are more likely to lead to improved student performance. Teachers' willingness to actively participate in conversations about issues around students' learning goals, teaching practices and students is critical to impact PLCs (Nelson et al. 2010: 175). In line with this view, Chapman et al. (2010: 54), Nelson et al. (2010: 175) and West (2010: 101) argue that PLCs among teachers may not only be the outcome of continuing professional development and collaboration, but that they may also enable professional learning, stimulate, support and sustain changes in practice and ultimately improve student performance. This view is succinctly supported by the South African National Policy Framework for Teacher Education and Development (Republic of South Africa 2007: 33): 'A professionally confident, fully capable and continually learning community of teachers is the necessary requirement for success.'

Teachers play a key role in the implementation of educational policies and need to be professionally equipped to meet the challenges associated with those policies. Such policies have often neglected to indicate the way in which continuing professional development programmes should be implemented in education systems (Bantwini 2009: 169; Gray 2005: 19; Pedder and Opfer 2011: 754). As a result governments are searching for research that guides them in providing effective continuing professional development for teachers through appropriate systems and strategies in schools (Republic of South Africa 2008: 4; Pedder and Opfer 2011: 741).

Maistry (2008: 139) advocates that more studies need to be done to understand the conditions that would enhance and sustain collaborative structures for teachers in schools, especially in a developing country such as South Africa. It is noteworthy that the 'Schools and Continuing Professional Development in England - State of the Nation' policy of 2008 in England has changed the main purpose of continuing professional development from a focus on the professional development of individual teachers to a system where schools are supported in their improvement priorities which are targeted at policy implementation and its effective management (Pedder et al. 2010: 367). School systems in the USA have also identified collaborative learning as a main strategy to ensure effective profes- sional growth among teachers (Darling-Hammond et al. 2009: 4). Little research has been done on aspects that are important for effective teacher collaboration and networking (Katz and Earl 2010: 27-28). The studies of Muijs et al. (2010: 24) and West (2010: 109) therefore call for research that can aid PLCs, collaboration and interdependence in schools, since this approach has the potential to ultimately enhance teacher and student learning.

Findings from previous studies show that the low ranking of the usefulness of most professional development programmes is a sign of the inappropriateness of many of these programmes in South Africa (Steyn 2009, 2010). The studies of Steyn $(2008,2009,2010,2011)$ report on various aspects of teachers' continuing professional development, in particular prior to the implementation of the National Policy Framework (Republic of South Africa 2007), but do not explicitly focus on understanding effective PLCs for the sake of teachers' professional development, particularly since the policy has been mandated from 2011. The Teacher Development Summit of 2009 expressed the need to identify suitable models of continuing teacher development in South Africa (Republic of South Africa 2011: 88). The question that emanated from this concern was: How can the continuous professional development of teachers be enhanced through teacher professional learning communities in schools?

\section{Continuing Professional Teacher Development in South Africa and Its Enforced Compliance}

Due to the legacy of apartheid that led to many teachers' poor content knowledge and social inequality, South Africa 'urgently needs more and better teachers' (Centre for Development and Enterprise 2011: 4). Although there has been an improvement in terms of formal qualifications, many South African teachers are 'poorly trained and utilised' and the poor performance of South African teachers is the main reason for the bleak performance by many schools in South Africa (Centre for Development and Enterprise 2011: 4). Moreover, this legacy has severely affected the culture of continuing professional development in schools (Mestry et al. 2009: 476).

In line with international trends, the provision of continuing, individualised and modified 
professional development opportunities for all teachers has become a key priority in South Africa (Armour and Makopoulou 2012: 337). The National Policy Framework for Teacher Education and Development (Republic of South Africa 2007) and the Integrated Strategic Planning Framework for Teacher Education and Development in South Africa (Republic of South Africa 2011) have been initiatives to contribute towards fulfilling the dire need for suitably, professionally qualified teachers in South Africa.

The ultimate aim of teachers' continuing professional development is an improvement of their teaching practice (Republic of South Africa 2011: 75). While the National Policy Framework supports teacher development activities, it does not explicitly refer to collaborative learning among teachers (Republic of South Africa 2007). In the Integrated Strategic Planning Framework collaboration among teachers plays more of a key role (Republic of South Africa 2011: 92). In line with international trends, participants at the Teacher Development Summit called for, inter alia, cooperative and collaborative working, networking and partnerships among all role players that should place the teacher firmly at the centre of teacher development activities, by establishing professional learning communities (Republic of South Africa 2011: 13).

Continuing professional development is mandatory for all registered South African teachers and aims to acknowledge and encourage (1) individual teachers' endeavours to improve their own learning and develop themselves professionally (2) teachers' participation in collectively developing themselves and improving learning within their schools; and (3) teachers' participation in professional development programmes offered by employers, unions and others to improve their learning and develop themselves (Republic of South Africa 2008: 5). The focus of this article is therefore on enhancing the collaborative learning of teachers.

Teachers must accumulate 150 professional development points within a three-year period (Republic of South Africa 2008: 5). These points are used to assign a numerical value to a particular professional development activity (Republic of South Africa 2008: 5). The points can be accumulated through three different types of activities (South African Council for Educators 2010: 29-30):
- Teacher priority activities that include those activities that teachers choose for their own professional development for improving their own professional practices, such as attending union and learning area meetings, doing research, assessing national examinations and attending workshops from their own funds.

- In school priority activities school leadership and staff collectively undertake development activities for the sake of whole school development which is considered to be the institutional conditions for improving teaching and learning, such as attending staff meetings, participate in school fund raising projects and attend and participate in curriculum workshops.

- Profession priority activities are directly linked to promote the professional status, commitments and practices of teachers in areas of which require development, such as attending workshops presented by accredited bodies and enrolling for formal qualifications from higher education institutions.

It is important that teachers be involved in all three categories in order to accumulate the necessary points. The implementation of the professional development points system will be completed by January 2014 (South African Teachers' Union 2009). The South African Council for Educators (SACE) as a statutory body is responsible for implementing, managing and ensuring the quality of the continuing professional development system (SACE 2011b: 9).

\section{Conceptual Perspectives on Professional Learning Communities}

Studies reveal that continuing professional development of teachers is complex, which explains why questions remain on how to conceptualise teachers' continuing professional development for the sake of meaningful learning improvement (Armour and Makopoulou 2012: 338; Kitchen 2009: 59; Sigurðardóttir 2010: 397). One reason may be that teachers' professional learning is shaped by the different classroom contexts in which teachers work. These, in turn, are shaped by their school culture and the society and community in which they teach (Timperley 2008: 6). 
Literature reveals a number of theories that shed light on understanding the development of adults' knowledge and skills (Grado-Severson 2007: 75; Ntapo 2009: 17). Theories of adult learning and constructivist learning explain how adults can be assisted when engaging in their own continuing professional development (Grado-Severson 2007: 75). Drawing on the adult learning theories of Kegan (1994) and Knowles (1984), significant principles emerge that underpin adult learning theories. These include the following: (1) Adults' personalities, needs, learning styles, work and life experiences influence their views on education, learning and ultimately continuing professional development; (2) Adults want to understand why it is necessary to learn something and require their learning to be of value and meaningful; (3) Both physical and psychological changes need to be acknowledged in adult learning; (4) To support adult learning social culture and social context need to be understood; and (5) Adults learn through experiences and approach learning in the form of problem-solving (Grado-Severson 2007: 76). To be effective developmental programmes need to respect adult learning principles that emphasise the construction of a personal understanding of an environment by means of reflection, interaction and action (Ntapo 2009: 17). A constructivist approach to teachers' learning focuses on learning that is negotiated through a collaborative social activity (Chalmers and Keown 2006: 148; Ntapo 2009: 17). It therefore seems that through shared meaning individuals within teams and groups learn and develop, and thereby incorporate both individual and social learning.

In line with social constructivism, Wenger's social learning theory focuses on learning as both an active and social involvement (Wenger 1999: 31 ) with the concept 'community of practice' at the centre of the theory (Ainscow 2010: 78). Wenger's theory implies that learning should be an essential part of an individual's involvement in organisations and communities of practice. Wenger (2000: 229) considers the notion of communities of practice as a condition for learning to occur that involves the creation and transfer of knowledge which is at the core of meaningful learning. Communities of practice within organisations develop when staff members as a social group are engaged in a process of sustained and shared collective learning (Wenger 2007: 1; Ainscow 2010: 78). This implies that the members in a community of practice need to trust one another and to provide opportunities to address and share practical problems (Wenger 2000: 230).

The communities of practice framework of Wenger has been viewed as a suitable way of describing collaborative initiatives where teachers have the opportunity to apply new strategies and reflect on these outcomes (Butler et al. 2004: 437; Desimone 2009: 182). It essentially focuses on the premise that individuals' construction of knowledge does not occur in a vacuum, but that constructing knowledge, skills, attitudes and beliefs is culturally and socially situated (Pedder et al. 2005: 215). Moreover, Maistry (2008: 132) believes that more meaningful teacher development occurs when teachers collaborate in ongoing and intensive interactions with their colleagues.

Other studies show that learning within organisations is repeatedly presented on two levels, the individual and the collective level. They maintain that individual learning is a crucial but an inadequate requirement for collaborative learning in organisations and organisational development (Chalmers and Keown 2006; Lee and Roth 2007). These findings suggest that combining learning as personal construction and learning as collaborative and workplace participation 'points towards more effective ways of understanding and improving learning' (Hodkinson and Hodkinson 2005: 114). In this regard Erichson (2007: 1) states: '[Learning] involves participation in constructive discourse to use the experience of others to assess reasons justifying these assumptions, and making an action decision based on the resulting insight.' Hirsh (2012: 64) elaborates on this view by stating that effective learning in communities requires three concepts: (1) Professionals: Who will participate in the community? Professionals include school leaders, teachers and other staff; (2) Learning: What is the work of the professional community? The needs of professionals in the learning community are paramount and their learning should cover both the knowledge and skills necessary to meet their identified needs; and (3) Community: How are professionals organised to achieve the set objectives? This implies that professional communities need to provide appropriate structures and processes to enhance learning and accelerate performance (Hirsh 2012: 64). 
The influences on teachers' professional learning cannot be studied in isolation since the features of continuing professional development activities, individual learning orientation and school-level learning orientation all mediate teachers' learning (Pedder et al. 2010: 389; Opfer et al. 2011: 196). Individual teachers need to develop certain skills for the sake of their own learning and development. They are encouraged to reflect on their teaching practice and to review their practices through various lenses for the sake of improved practice and to realise the benefits of collaborative continuing professional development (Katz and Earl 2010: 31; Printy 2010: 115). Pedder et al. (2010: 389) explain that teachers' values and practice endorsed at individual teacher level are re-endorsed at school level where collective and socially constructed conditions for professional learning (a school-level orientation) are created. School-level influences include the school context and conditions that sustain teaching and learning, the role of leadership, the shared beliefs and views about learning, the shared norms of practice or the practices that exist within the school and the shared capacity to accomplish shared learning goals (Pedder et al. 2010: 389; Sigurðardóttir 2010: 407). As such Pedder and Opfer (2011: 196) argue that teacher learning occurs primarily as the outcome of their interaction of collective beliefs, support and systems, which have a major impact on their individual learning. This means that professional learning can only be understood when understanding the role which the school plays in teachers’ learning (Pedder and Opfer 2011: 196).

New models on PLCs are emerging (Katz et al. 2008: 112). So-called communities of practice (Ainscow 2010: 77), learning team model (Chappuis et al. 2009: 57), professional networks and affiliation networks (Smith and Wohlstetter 2001: 501), workplace learning (Hodkinson and Hodkinson 2005: 128), networked learning communities (Katz and Earl 2010: 27) and collaborative practices (Chapman and Allen 2006: 291) are concepts used to describe professional learning among teachers. Such models support the idea that the knowledge of individuals is not constructed in a vacuum, but that such construction is rather culturally and socially situated (Butler et al. 2004: 438).

Chappuis et al. (2009: 57) advocate a learning team model of professional development to enhance 'deeper, ongoing teacher-directed learn- ing' which removes teacher isolation as a barrier to effective professional development and quality teaching (Printy 2010: 125). Printy's study shows the power of professional communities in schools and supports the fact that teacher isolation is an 'anathema' to quality teaching (Printy 2010: 125). The models on collective learning focus on a deeper, more continually, collaborative, on-the job teacher-directed learning which is required for teachers' effective growth (Chappuis et al. 2009: 57; Darling-Hammond et al. 2009: 2). Professional learning through collaboration is regarded as in 'intensive interaction that engages educators in opening up their beliefs and practices to investigation and debate' (Katz and Earl 2010: 30). Based on research literature, a set of characteristics that constitutes PLCs can be identified: A shared vision for learning and the shared responsibility for student performance; a primary focus on teaching and learning; a focus on continuous improvement; collective investigation of teaching practice; reliance on reflection, experimentation and dialogue in practice; scheduled opportunities for collaboration; and a sincere commitment to effective learning for all students (Nehring and Fitzsimons 2011: 515; Sigurðardóttir 2010: 397).

\section{METHODOLOGY}

A qualitative research design involving a conceptual study was deemed the most appropriate for the study. The purpose was to add to the existing body of knowledge and understanding of the phenomenon of peer collaboration in implementing continuing professional development in the National Policy Framework (Republic of South Africa 2007) and the Integrated Strategic Planning Framework (Republic of South Africa 2011a) more effectively (Nieuwenhuis 2010: 71).

Data collection methods therefore involved a review of official documents (Strydom and Delport 2011: 377) and literature on continuing professional development (Nieuwenhuis 2010: 82), in particular on PLCs through teacher collaboration and teacher networks. A theoretical foundation of PLCs could deepen and inform the implementation of such communities for the sake of teachers' effective continuing professional development and ultimately improve school performance and student learning. The research problem was therefore approached from a prag- 
matic perspective, since the effectiveness of the implementation of continuing professional development in school practice was viewed as very important. This is also in line with Mundry (2005: 14), who states that education managers and policy makers should invest in these more 'practice-based’ approaches to professional learning for teachers. Data analysis of the collected official documents entailed a content analysis, which is regarded as a systematic approach to analyse qualitative data (Nieuwenhuis 2010: 101; Strydom and Delport 2011: 384).

\section{FINDINGS AND DISCUSSION}

\section{Guidelines for Professional Learning Communities in Schools}

Continuing professional development is viewed as a dynamic, job-embedded, classroomfocused, supportive, collaborative and ongoing process that actively involves teachers in learning and development opportunities (Hunzicker 2010: 2; Murtaza 2010: 213). This view explains why traditional approaches to continuing professional development, which usually include one-day workshops where teachers are provided with information that they need to apply in practice, have been criticised (Chappuis et al. 2009: 57; Hunzicker 2011: 177; Republic of South Africa 2011b: 88). Such programmes may raise the awareness of certain topics or create a foundation of knowledge, but do not lead to sustained continuing professional development or improved practice (Chappuis et al. 2009: 57; Hunzicker 2011: 177).

As mentioned before, many educational systems are developing collaborative approaches through formal professional learning networks to improve the quality of schooling (Chapman et al. 2010: 56; Muijs et al. 2010: 6; West 2010: 101). Such approaches to teachers' learning acknowledge that shared learning activities may lead to new learning which ultimately impacts practices and leads to school improvement (Katz and Earl 2010: 28; Muijs et al. 2010: 7; West 2010: 101).

The study of Katz and Earl (2010: 43) conclusively shows that schools are the places where 'new knowledge and conceptual change operate to change how teachers and head teachers/ principals think and act', thus improving student performance. However, the social school climate, appropriate school structures to promote col- laboration, shared leadership, mutual support for continuing professional development and cultural factors such as the beliefs of staff and leadership in schools may impact professional learning (Sigurðardóttir 2010: 397; Moloi et al. 2002: 93).

Based on the conceptualisation of PLCs, the following serve as guidelines in expanding continuing professional development opportunities through collaborative learning for teachers:

\section{A Clear Learning Focus on and Commitment to Professional Learning}

An accurate learning focus of PLCs is based on proof that they can have a meaningful impact on both daily classroom practices and student performance and acknowledge the context, needs and history of that particular school (Desimone 2009: 182; Hunzicker 2010: 5; Katz and Earl 2010: 29; Katz et al. 2008: 128). That is why Hunzicker (2011: 178) and as well as Pedder and Opfer (2011: 754) propose that continuing professional development programmes should be mainly schoolbased and focus on teacher learning processes and how to improve teachers' practice.

In their study Katz and Earl (2010: 41, 42) found that only through teachers' 'intensive involvement' in PLCs did significant positive changes in school practices occur which led to improved student performance. However, mere membership of such communities is not sufficient to improve school or student performance (Katz and Earl 2010: 42). Teachers instead require rigorous, job-embedded, 'hands-on' opportunities to build their knowledge of the subject content and skills to teach students in collaboration with colleagues (Darling-Hammond et al. 2009: 10). This type of learning is embedded in teachers' daily work where they obtain new knowledge and skills, apply them in practice and from their experiences acquire more knowledge (Sigurðardóttir 2010: 397).

One crucial feature of effective continuing professional development and teachers' active involvement in PLCs lies in teachers' sincere commitment and willingness to participate and learn in learning communities (National Comprehensive Centre for Teacher Quality 2011: 5; Mestry et al. 2009: 488; Moloi et al. 2002: 93; Ntapo 2009: 43). Katz and Earl (2010: 43) refer to the necessity of 'changes in the hearts and 
minds' of teachers before real changes can occur in their own and students' learning.

It is also important that teachers value the learning content and realise the possibility of integrating what they have learnt into their classroom practice (Hodkinson and Hodkinson 2005: 122). These aspects are also in line with adult learning theories where teachers need to acknowledge the value of learning as well as other models of collaboration that propose that the construction of an individual's knowledge and skills does not occur in a vacuum, but that it is culturally and socially situated (Chappuis et al. 2009: 57). Implied in a collaborative focus and collective commitment among teachers is the existence of conducive relationships among colleagues.

\section{Conducive Relationships in Professional Learning Communities}

Ainscow (2010: 88) believes that successful PLCs require new relationships and thinking at school level. Such relationships form the basis of learning communities and allow staff to work together in such a way that will exceed any individual accomplishment (Katz and Earl 2010: 29). Through suitable professional relationships, teachers create a sense of shared responsibility and a common language, and are able to create the necessary channels for communication (Katz and Earl 2010: 29-30; Katz et al. 2008: 118; Supovitz et al. 2010: 35). This also contributes towards improved communication, respect and trust within a collegial school atmosphere (Bezzina 2002: 79). When supportive interactions in professional communities among teachers occur, such teachers may be able to assume roles such as mentor, mentee, expert and facilitator (Louis et al. 2010: 319).

Conducive relationships between teachers provide opportunities for teachers to remove isolation as a barrier to the quality of education. Moreover, for teachers to engage solely in individual learning opportunities separated from their colleagues, with no follow-up or feedback, is ineffective for teacher development (National Comprehensive Centre for Teacher Quality 2011: 7). A conducive professional relationship among colleagues supports the social learning theory of Wenger where staff members as a social group form the foundation for meaningful learning (Wenger 2000: 229). PLCs, however, include more than mere relationships, since they refer to intensive interaction in which teachers are engaged so that their practices and beliefs can be investigated and debated (Katz and Earl 2010: 30; Katz et al. 2008: 118).

\section{Professional Learning Communities for Schools}

Professional collaborative learning in schools denotes an important aspect of 'deep structures' of learning (Pedder and Opfer 2011: 742) and is a crucial requirement for effective professional learning and school improvement (Chapman et al. 2010: 54; Republic of South Africa 2011b: 75; Desimone 2009: 184; Hunzicker 2011: 178; Ntapo 2009: 28). Workshops, which are often decontextualised from classroom practice with limited collaboration among teachers, rarely impact teacher learning or their teaching practice (Pedder and Opfer 2011: 754). This implies that schools need to guide teachers to participate in appropriate continuing professional development programmes and to support and provide access to such programmes (Opfer et al. 2011: 196; Pedder et al. 2010: 389). Furthermore, such continuing professional development opportunities should also provide for active learning with the necessary follow-up as well as feedback to promote change in teachers' practice (National Comprehensive Centre for Teacher Quality 2011: 6).

To implement the professional learning team model in schools the following should be considered:

- Create a Clear Understanding of PLCs: Schools need to create a clear understanding of the professional learning team process in which teams work collaboratively to enhance classroom practice (Pedder and Opfer 2011: 754). Moreover, as long as teachers view a PLC as an 'option' which they can ignore or use, school-wide change is unlikely to happen (Chappuis et al. 2009: 57; Nehring and Fitzsimons 2011: 527). For effective professional learning to occur, regular opportunities to work collaboratively are required (Nehring and Fitzsimons 2011: 524), which can be scheduled in the school's annual programme (Republic of South Africa 2011b: 82). School days can also be rearranged to allow school-secured time for teachers to collaborate by means of, inter alia, staff meetings, training les- 
son planning, workshops or expert facilitators (Reyes and Wagstaff 2005: 111). At structural level this implies that schools need to develop suitable collaborative structures that will enhance teachers' professional learning (Pedder and Opfer 2011: 754).

- Identify Suitable Facilitators for PLCs: Schools need to identify suitable facilitators who are able to facilitate discussions, to assist in transferring acquired knowledge into the classroom and to select appropriate learning activities that match the teams' needs (Chappuis et al. 2009: 57). The focus should be on long-term, ongoing continuing professional development activities instead of short-term quick fixes.

- Create a Safe, Supportive Environment for PLCs: Teachers in the same school should share problems, knowledge and skills during interactive continuing professional development opportunities within a safe, supportive environment (Armour and Makopoulou 2012: 342; Harwood and Clarke 2006: 29; Hunzicker 2010: 6; Printy 2010 : 125). In such communities teachers should have the opportunities to share their experiences of students' learning and classroom materials and also obtain feedback on their teaching practice within a supportive environment (Maistry 2008: 132; National Comprehensive Centre for Teacher Quality 2011: 5). Once teachers are involved in a 'dynamic process of interpretation and evaluation of practice', they promote their own practice and that of the profession (Katz and Earl 2010: 30).

It is important to realise that collegial interactions may not be enough to change the status quo (Katz and Earl 2010: 43). The type of interaction that may influence knowledge creation and conceptual change includes collegial dialogue between teachers who openly share their differing opinions, values and views regarding teaching (Katz and Earl 2010: 45). Collegial dialogue explores teaching and learning more deeply instead of consisting of 'congenial conversations' which are more superficial in nature (Nelson et al. 2010: 175). To be effective, collegial dialogue assumes a level of personal confidence and trust which allows teachers to be willing, honest and transparent to review their own practices and beliefs (Katz and Earl 2010: 45; Katz et al. 2008:
118). For this to occur, a 'cycle of inquiry' is required on a particular topic, in which they identify a shared vision for that aspect and then start identifying gaps in this vision and their current practice (Nelson et al. 2010: 175). Such acquired knowledge should then be implemented and its impact on student learning determined by collecting and analysing classroom-based information.

- Involve Principals in PLCs: Schools and school leadership need to play an important role in supporting the professional learning of teachers (Pedder and Opfer 2011: 743) and to increase the depth of collaborative dialogue in PLCs (Nelson et al. 2010: 178). Principals exert greater impact on teachers' practice when they work jointly with teachers on aspects that influence their classroom practice (Printy 2010: 113). Nehring and Fitzsimons (2011: 518, 524), Printy (2010: 113) and Timperley (2008: 20,22 ) regard it as the responsibility of school leaders to provide appropriate professional learning for teachers. This responsibility includes three leadership roles to ensure that teachers' learning is focused and ongoing: (1) Developing a vision for teachers' professional development for the sake of teachers' learning, improved student performance and school improvement (Masitsa 2005: 212; Supovitz et al. 2010: 34); (2) Leading teachers' learning by helping them to understand new developments and by engaging them constructively in disagreements. These activities include experimenting with and changing the classroom practice; acting on feedback from colleagues and pupils; mentoring; inschool workshops based on research findings; self-evaluation; collaborative research and participation in teacher networks (Pedder and Opfer 2011: 746); (3) Providing and organising well-managed, productive learning opportunities for the sake of prolonged and in-depth professional learning (Moswela 2006: 630). This implies that strategic planning is required for the development and support of an expansive learning environment in schools (Hodkinson and Hodkinson 2005: 127). Verification of teachers' development is also required so that strategies can be amended and changed for the sake of effective 


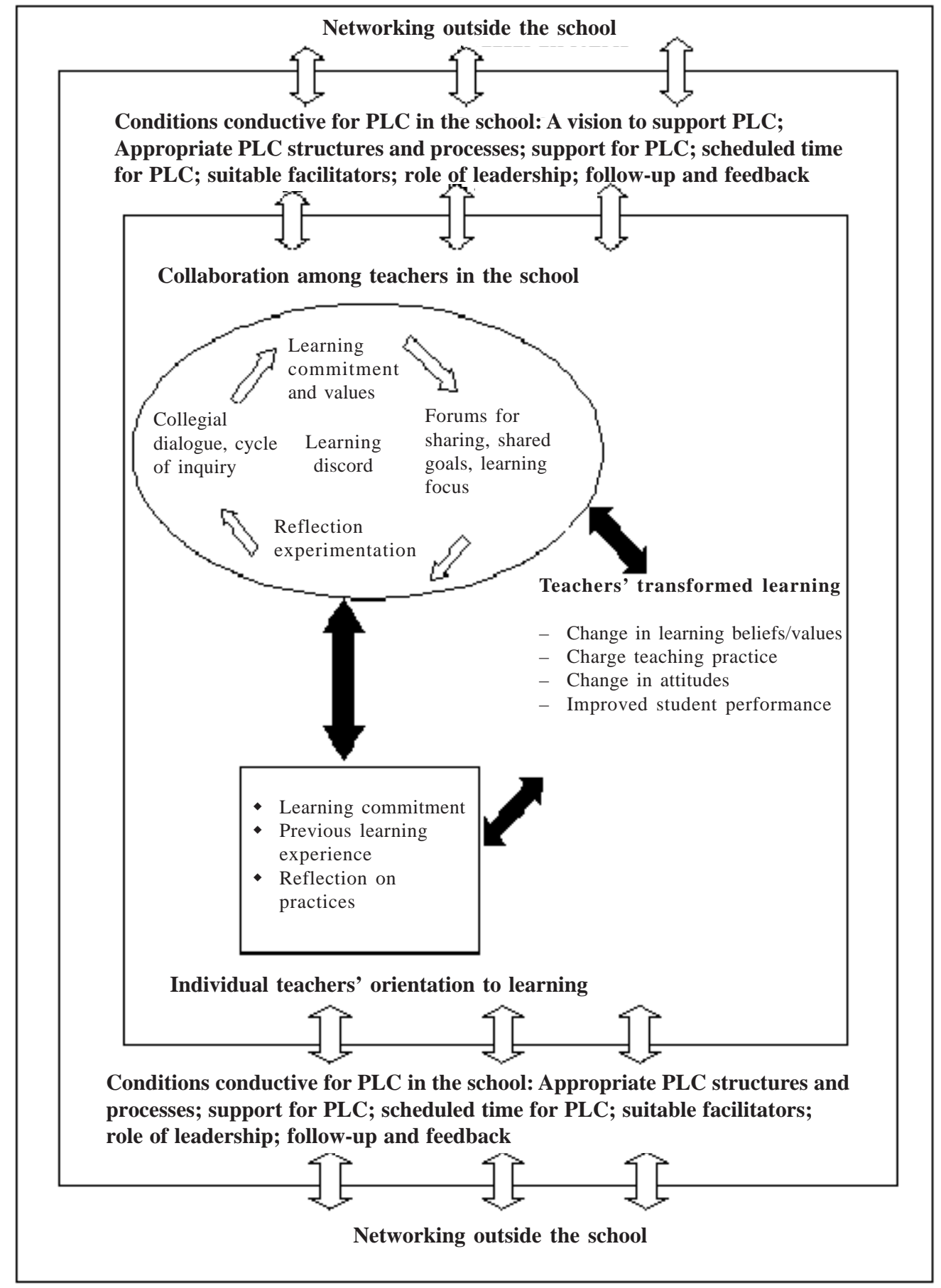

Fig. 1. A dynamic model of professional learning communities 
collaborative learning in schools. It is important to note that it is unlikely that mere pressure on school leaders to bring about necessary changes for principal-teacher collaboration will occur without the appropriate and practical support within their complex school settings (Louis et al. 2010: 332).

- Provide the Necessary Support and Building Capacity for PLCs: Studies by Pedder (2006) and Pedder et al. (2010: 34-36) show a significant relationship between certain school factors, such as support for teachers' learning and collaboration and the level of teachers' learning. This implies that schools that strive to develop and sustain the quality of their teachers need to design and develop appropriate processes and practices for teacher learning (Pedder 2006: 175; Pedder and Opfer 2011: 195). Creating such conditions proves to be difficult for some schools and not all schools may acknowledge the necessity to create such learning environments (Pedder and Opfer 2011: 195) unless they are compelled to do so.

- Network with Other Schools: Networking among the teachers of different schools has the potential to widen the scope for teachers to engage and have access to diverse teaching practices and also to enhance opportunities for teachers to be involved in problem-solving and to create the transfer of knowledge (Pedder and Opfer 2011: 743). West (2010: 96) believes that schools have been viewed incorrectly and that individual schools should rather be viewed as 'untapped resources' in the education system to improve their quality. Schools that develop network opportunities which are more equal and collegial than 'a simple good school-weak school combination' seem to enhance the quality of schooling (Chapman et al. 2010: 69). These schools consequently succeed in developing firm interdependent relationships among teachers who learn from one another and who work on a common task, such as developing the curriculum and planning timetables (Ainscow 2010: 78; Chapman et al. 2010: 69). Once individual teachers actively engage in these PLCs, they serve as 'connectors' of schools to networks and vice versa (Katz and Earl 2010: 29).

Engaging poor-performing schools in collaborative, networking approaches may be challenging for reasons that include tension, fear, suspicion or a history of isolation between staff members (Chapman and Allen 2006: 298; Chapman et al. 2010: 62; Muijs et al. 2010: 6; West 2010: 101). This implies that networking between schools needs to be negotiated to allow the identification of appropriate strategies for improvement (Chapman and Allen 2006: 298). The success of the collaboration will depend on the mutual trust between staff members and their willingness to work together (Chapman and Allen 2006: 298; West 2010: 103).

The aspects outlined above can be depicted in Figure 1, which shows how individual learning, professional development communities, a conducive school environment and networking lead to transformational change in teachers.

\section{CONCLUSION}

Previous literature on professional development focuses on teachers' learning as a predominantly individual process of construction, while the literature on professional learning emphasises learning through collaborative involvement in everyday school practices. It is therefore recommended that by merging these approaches and including the imperative role of a conducive school environment, the role of leadership and networking, the concept of an expanded, professional learning environment emerges that increases the potential for more effective teacher development and learning.

Collaborative learning in schools needs to be carefully planned and organised in such a way that teachers are regularly engaged and that all learners can benefit from this approach. Considering the discussion in this study, the following conclusions can be made:

- Although studies confirm the important role that teacher collaboration plays in increasing school and student performance, there are barriers to achieve this. Isolation between teachers may hinder the development of such practices and therefore limit the opportunities for teachers to develop their professional knowledge and skills. As such, teacher isolation needs to be addressed for the 
sake of professional learning opportunities among staff members.

- The need for professional learning opportunities in schools may vary depending on school contexts and teacher competence. Some schools may experience difficulties in developing professional learning opportunities. School leaders need to be assisted in developing appropriate collaborative structures in schools for the sake of improved teacher learning and classroom performance.

- To extend professional learning among teachers in schools to network with other schools requires particular management skills, which include carefully selecting schools in networks and also developing a staff development strategy that will enhance collaboration among staff in these schools.

Although professional learning has its challenges, learning opportunities with colleagues is an indispensable requirement to improve the quality of education in South Africa. Collaboration among teachers in schools may provide exposure to new ideas and opportunities to learn together and enhance their professional development. I agree with Katz et al. (2008:134) that 'explicit, conscious, and intentional strategies to support teachers in examining, understanding, and sharing practice within schools and across networks must be undertaken in order to help networks contribute to the cultivation of innovative knowledge communities'.

\section{REFERENCES}

Ainscow M 2010. Achieving excellence and equity: Reflections on the development of practices in one local district over 10 years. School Effectiveness and School Improvement, 21(1): 75-92.

Armour KM, Makopoulou K 2012. Great expectations: Teacher learning in a national professional development programme. Teaching and Teacher Education, 28: 336-346.

Bantwini BD 2009. District professional development models as a way to introduce primary school teachers to natural science curriculum reforms in one district in South Africa. Journal of Education for Teaching, 35(2): 169-182.

Bezzina C 2002. Preparing a model of professional development schools in Malta. Curriculum and Teaching, 17(2): 73-84.

Butler D L, Lauscher H J N, Jarvis-Selinger S, Beckingham B 2004. Collaboration and self-regulation in teachers' professional development. Teaching and Teacher Education, 20(5): 435-455.

Centre for Development and Enterprise 2011. Informing South African Policy (CDE in Depth no 11). Values in the Classroom. The Quantity and Quality of South Africa's Teachers. From < http:// getideas.org/resource/value-in-the-classroom-thequantity-and-quality-of-south-africas-teachers/> (Retrieved February 16, 2012).

Chalmers L, Keown P 2006. Communities of practice and professional development. International Journal of Lifelong Learning, 25(2): 139-156.

Chapman C, Allen T 2006. Collaborative reform for schools in difficulty. Improving Schools, 9(3): 291301.

Chapman C, Lindsay G, Muijs D, Harris A, Arweck E, Goodall J 2010. Governance, leadership, and management in federations of schools. School Effectiveness and School Improvement, 21(1): 53-74.

Chappuis S, Chappius J, Stiggins R 2009. Supporting teacher learning teams. Association for Supervision and Curriculum Development, 66(5): 56-60.

Darling-Hammond L, Wei RC, Andree A, Richardson N, Orphanos S 2009. Professional Learning in the Learning Profession: A Status Report on Teacher Development in the United States and Abroad. Dallas, TX: National Staff Development Council. From <http://www.nsdc.org/news/NSDCstudy2009. pdf $>$ (Retrieved February 13, 2012).

Desimone LM 2009. Improving impact studies of teachers' professional development: Toward better conceptualizations and measures. Educational Researcher, 38(3): 181-199.

Desimone LM, Smith TM, Ueno K 2006. Are teachers who need sustained, content-focused professional development getting it? An administrator's dilemma. Educational Administration Quarterly, 42(2): 179-215.

De Vos AS, Strydom H, Fouche CB, Delport CSL 2005. Research at Grassroots for the Social Sciences and Human Service Professions. $3^{\text {rd }}$ Edition. Pretoria: Van Schaik.

Erichson EA 2007. Transformative Learning Theory. From <http://uwstudentfpweb.uwyo.edu/E/ERICHSEN/Resource\%20Guide\%20Assignment.pdf> (Retrieved March 10, 2009).

Grado-Severson E 2007. Helping teachers learn; principals as professional development leaders. Teachers College Record, 109(1): 70-125.

Gray SL 2005. An Enquiry into Continuing Professional Development for Teachers. University of Cambridge: Esmee Fairbairn Foundation.

Hallinger P, Heck RH 2010. Collaborative leadership and school improvement: Understanding the impact on school capacity and student learning. School Leadership and Management, 30(2): 95 110.

Harwood T, Clarke J 2006. Grounding continuous professional development in teaching practice. Innovations in Education and Teaching International, 43(1): 29-39.

Hirsh S 2005. Professional development and closing the achievement gap. Theory into Practice, 44(1): 38-44.

Hirsh S 2012. A professional learning community's power lies in its intentions. Journal of Staff Development, 33(3): 64 . 
Hodkinson H, Hodkinson P 2005. Improving school teachers' workplace learning. Research Papers in Education, 20(2): 109-131.

Hunzicker JL 2010. Characteristics of Effective Professional Development: A Checklist. From ERIC database (ED510366). From <http://www.eric. ed. gov/PDFS/ED510366.pdf> (Retrieved February 16, 2012).

Hunzicker JL 2011. Effective professional development for teachers: A checklist. Professional Development in Education, 37(2): 177-217.

Katz S, Earl L 2010. Learning about networked learning communities. School Effectiveness and School Improvement, 21(1): 27-51.

Katz S, Earl L, Jaafar S, Elgie S, Foster L, Halbert J, Kaser L 2008. Learning networks. The key enablers of successful knowledge communities. McGraw Journal of Education, 43(2): 111-138.

Kegan R 1994. In Over Our Heads: The Mental Demands of Modern Life. Cambridge: Harvard University.

Kennedy A 2005. Models of continuing professional development. Journal of In-service Education, 31(2): 235-250.

Kitchen J 2009. Relational teacher development: Growing collaboratively in a hoping relationship. Teacher Education Quarterly, 36(2): 45.

Knowles M 1984. The Adult Learner: A Neglected Species. $3^{\text {rd }}$ Edition. Houston, TX: Gulf.

Lee Y-J, Roth W-M 2007. The individual/collective dialectic in the learning organization. The Learning Organization, 14(2): 92-107.

Louis KS, Dretzke B, Walhstrom K 2010. How does leadership affect student achievement: Results from national US survey. School Effectiveness and School Improvement, 21(3): 315-336.

Maistry SM 2008. Towards collaboration rather than co-operation for effective teacher professional development in South Africa: Insights from social practice theory. Southern African Review of Education, 14(1): 119-142.

Masitsa MG 2005. The principal's role in restoring a learning culture in township secondary schools. African Education Review, 2(2): 205-220.

Mestry R, Hendricks I, Bisschoff T 2009. Perceptions of teachers on the benefits of teacher development programmes in one province of South Africa. South African Journal of Education, 29: 475490.

Moloi KC, Grobler BR, Gravett SJ 2002. Educators' perceptions of the school as a learning organization in the Vanderbijlpark - North District, South Africa. South African Journal of Education, 22(2): 88-94.

Moswela B 2006. Teacher professional development for the new school improvement: Botswana. International Journal of Lifelong Education, 25(6): 625-632.

Muijs D, West M, Ainscow M 2010. Why network? Theoretical perspectives on networking. School Effectiveness and School Improvement, 21(1): 526.

Mundry S 2005. Changing perspectives in professional development. Science Educator, 14(1): 9-15.

Murtaza KF 2010. Teachers' professional development through Whole School Improvement Program
(WSIP). International Journal of Business and Social Science, 1(2): 213 - 221.

National Comprehensive Centre for Teacher Quality 2011. High-quality Professional Development For All Teachers: Effectively Allocating Resources. Research and Policy Brief. From <http://www.tqsource. org/publications/HighQuality Professional Development.pdf> (Retrieved 13 February, 2012).

Nehring J, Fitzsimons G 2011. The professional learning community as subversive activity: Countering the culture of conventional schooling. Professional Development in Education, 37(4): 513-535.

Nelson TH, Deuel A, Slavit D, Kennedy A 2010. Leading deep conversations in collaborative inquiry groups. The Clearing House, 83: 175-179.

Nieuwenhuis J(2010. Qualitative research designs and data gathering techniques. In: K Maree (Ed.): First Steps in Research. Pretoria: Van Schaik, pp. 7097.

Ntapo ND 2009. A Critical Study of Continuing Professional Development Orientation Programme for Educators. M Ed Dissertation, Unpublished. Pretoria: University of Pretoria.

Opfer VD, Pedder D, Lavicza X 2011. The influence of school orientation to learning on teachers' professional learning change. School Effectiveness and School Improvement, 22(2): 193-214.

Pedder D, James M, Macbeath J 2005. How teachers value and practise professional learning. Research Papers in Education, 20(3): 209-243.

Pedder D, Opfer VD 2011. Are we realising the full potential of teachers' professional learning in schools in England? Policy issues and recommendations from a national study. Professional Development in Education, 37(5): 741-758.

Pedder D, Opfer VD, McCormick R,Storey A 2010. Schools and continuing professional development in England - State of the Nation' research study: Policy context, aims and design. The Curriculum Journal, 21(4): 365-394.

Printy S 2010. Principals' influence on instructional quality: Insights from US schools. School Leadership and Management, 30(2): 111-126.

Rademeyer A 2012. Onderwys ' $\mathrm{n}$ misdaad [Education a crime], March 5, 2012, Beeld, P. 4.

Republic of South Africa 2007. National Policy Framework for Teacher Education and Development in South Africa. Government Gazette 503, No. 29868. Pretoria: Government Printer.

Republic of South Africa, Department of Basic Education 2008. The Design of the Continuing Professional Development (CPTD) System. South African Council for Educators. From <http://www.sace. org.za/upload/files/CPTD\%20Design\%20 doc\% 20draft\%20version\%2013A\% 20100 6081.pdf > (Retrieved August 13, 2012).

Republic of South Africa 2011. Integrated Strategic Planning Framework for Teacher Education in South Africa. 2011 - 2025. From <http://www. naptosa. org.za/publications/TED.pdf> (Retrieved August 13, 2012).

Republic of South Africa, Department of Basic Education 2011. Integrated Strategic Planning Framework for Teacher Education and Development in 
South Africa. Technical report: Departments of Basic Education and Higher Education and Training. From <http://getideas.org/resource/integratedstrategic-planning-framework-teacher-educationand-development-south-af/> (Retrieved February 16, 2012).

Reyes P, Wagstaff L 2005. How does leadership promote successful teaching and learning for diverse students? In: WA Firestone, C Riehl (Eds.): A New Agenda for Research in Educational Leadership. New York, NY: Teachers College, Columbia University, pp. 101-118.

Sigurðardóttir AK 2010. Professional learning community in relation to school effectiveness. Scandinavian Journal of Educational Research, 54(5): 395-412.

Smith AK, Wohlstetter P 2001. Reform through school networks: A new kind of authority and accountability. Educational Policy, 15(4): 400-519.

South African Council for Educators 2010. The CPTD Management System Handbook. Version 2.

South African Council for Educators (SACE) 2011a. About CPTD. From <http://www.sace.org.za/ CPTD/jit_default_7.About_CPTD.html $>\quad(\mathrm{Re}-$ trieved February 27,2012 ).

South African Council for Educators (SACE) 2011b. Strategic Plan. From <http://www.sace.org.za/upload/files/SACE\%20Strategic\%20Plan.pdf> (Retrieved February 21, 2012)

South African Teachers' Union 2009. Continuous Professional Development. 7/2009. From <www. saou.co.za> (Retrieved August 18, 2012).

Steyn GM 2008. Continuing professional development for teachers in South Africa and social learning systems: Conflicting conceptual frameworks of learning. Koers, 73(1): 15-31.
Steyn GM 2009. Effective implementation of continuing professional development for South African teachers. Acta Academica, 41(2): 256-279.

Steyn GM 2010. Educators' perceptions of continuing professional development for teachers in South Africa: A qualitative study. African Education Review, 7(1): 343-365.

Steyn GM 2011. Implementing continuing professional teacher development: Policy and practice. Acta Academica, 43(1): 211-233.

Strydom H, Delport CSL 2011. Information collection: Document study and secondary analysis. In: AS De Vos, H Strydom, CB Fouche, CSL Delport (Eds.): Research at Grass Roots for the Social and Human Service Professions. $4^{\text {th }}$ Edition. Pretoria: Van Schaik.

Supovitz J, Sirinides P,May H 2010. How principals and peers influence teaching and learning. Educational Administration Quarterly, 46(1): 31-56.

Timperley H 2008. Teacher Professional Learning and Development. UNESCO/International Academy of Education, From <http://www.ibe.unesco.org/fileadmin/user_upload/Publications/Educational Practices/EdPractices_18.pdf > (Retrieved February 14, 2012).

Wenger E 1999. Learning as social participation. Knowledge Management Review, 6: 30-33.

Wenger E 2000. Communities of practice and social learning systems. SAGE Social Science Collection, $7(2): 225-246$.

Wenger E 2007. Communities of Practice. Third Annual National Qualifications Framework Colloquium, 5 June, Velmore Conference Estate.

West M 2010. School-to-school cooperation as a strategy for improving student outcomes in challenging contexts. School Effectiveness and School Improvement, 21(1): 93-112. 